\title{
DEVELOPMENT OF COMPRESSIVE STRENGTH AND MICROSTRUCTURE FOR CEMENT PASTE AND MORTAR CONTAINING $\mathrm{Cu}-\mathrm{Zn}$ NANO-FERRITES
}

\author{
Mounir M. Kamal ${ }^{1}$, Mohamed Safan ${ }^{1}$, Saaid I. Zaki ${ }^{2}$ \\ Mohamed Eltabey ${ }^{3}$, Khaled M. Abu El-hasan ${ }^{4}$ \\ ${ }^{1}$ Civil Engineering Department, Faculty of Engineering, Minoufiya University, \\ Shebin El-Kom, Egypt \\ ${ }^{2}$ Building Materials Research and Quality Control Institute, Housing \& Building National Research \\ Center, HBRC, Cairo, Egypt \\ ${ }^{3}$ Basic Engineering Science Department, Faculty of Engineering, Minoufiya University, \\ Shebin El-Kom, Egypt \\ ${ }^{4}$ Civil Engineering Department, Faculty of Engineering, Delta University for Science and Technology, \\ El-Mansoura, Egypt
}

\begin{abstract}
Nano ferrite/cement composites (NFCC) have been prepared by adding different weight ratios of Nano ferrite (N.F) ranging from (1 up to 4\%) cement. This study is aimed to evaluate the effect of addition of N.F on the mechanical behavior of NFCC and study the performance of cement pastes and cement mortars mixed with Nano ferrite (N.F) when exposed to elevated temperatures of 200 $\mathrm{oC}$ and $400 \mathrm{oC}$, for firing period of two hours. Compressive strength test showed valuable enhancement in mechanical properties of NFCC with increasing N.F loading ratio. The obtained minerals of $\mathrm{Cu}-\mathrm{Zn}$ ferrites nanoparticles were identified by using X-ray diffraction (XRD) and the morphology of N.F was determined using transmission electron microscopy (TEM). The microstructure of the NFCC was characterized by means of scanning electron microscope (SEM) analysis. The addition of N.F by about $1 \%$ enhanced the compression strength to about $52 \%$ for cement paste and $1 \%$ enhanced the compression strength to about $35 \%$ for cement mortar. The results indicated that cement pastes and cement mortars mixedwith N.F are more able to resist elevated temperature than pure cement pastes.

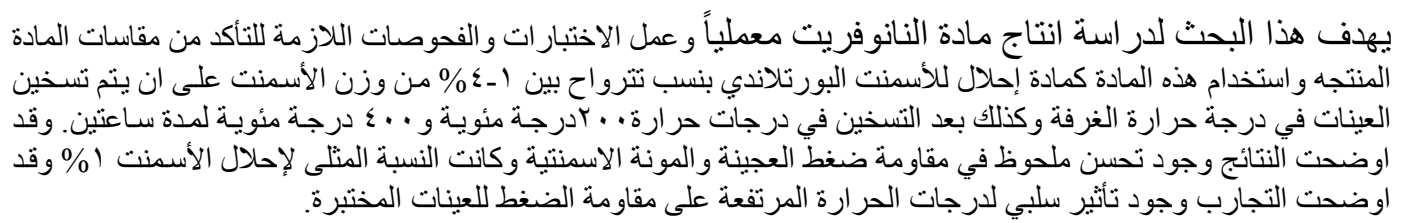

Keywords: Nano ferrite (N.F), TEM, SEM, microstructure, compressive strength, Nano ferrite/cement composites (NFCC).

\section{INTRODUCTION}

Concrete is one of the most common and widely used construction materials. Its properties have been well studied at structural level without fully understanding the properties of the cementitious materials at the micro level. The rapid development of new experimental techniques makes it possible to study the properties of cementitious materials at micro/nano-scale. Research has been conducted to study the hydration process, alkali-silicate reaction (ASR), and fly ash reactivity using nanotechnology [1].The better understanding of the structure and behavior of concrete at micro/nano-scale could help to improve concrete properties.

Addition of nanoscale materials into cement could improve its performance. $\mathrm{Li}$ (2004) found that nano$\mathrm{SiO} 2$ could significantly increase the compressive strength for concrete, containing large volume fly ash, at early age and improve pore size distribution by filling the pores between large fly ash and cement particles at nanoscale[2]. The dispersion/slurry of amorphous nanosilica is used to improve segregation resistance for self-compacting concrete [3]. It is also been reported that adding small amount of carbon 
nanotube $(1 \%)$ by weight could increase both compressive and flexural strength.

A nanoparticle is a microscopic particle whose size is measured in nanometres ( $\mathrm{nm})$. It is defined as particle with at least one dimension less than 100nm. Nanoparticles made of semiconducting material (material that is between a conductor and insulator e.g. silicon) may also be labeled quantum dots if they are small enough (typically sub 10nm) such that jumps in energy levels occur. The importance of this is that the same material of different sizes can emit different colours when energized with, for instance, UV light. Carbon Nanotubes are a sub set of nanoparticles.

The most widely conducted studies on the use of nanoparticles in cement and concrete have been on nano-oxides, especially $\mathrm{SiO} 2$ and $\mathrm{Fe} 2 \mathrm{O} 3$ [3-11]. The addition of these nanoparticles to cement paste containing high volumes of fly ash and to sludge ash concrete mortars resulted in an increase in compressive strength. Nano-Fe2O3 and nano-SiO2 were also used to increase the abrasion resistance of concrete for pavement [12]. Nano- $\mathrm{Ca}(\mathrm{OH}) 2$ particles have been prepared and their thermal properties were characterized to study the anomalous behaviors of $\mathrm{Ca}(\mathrm{OH}) 2$ in cement paste [13]. Also, other nano to sub-micro inorganic particles, such as zeolite, have been added to cement systems with the goal to improve the overall microstructure [14]. Another nanosize oxide of interest to construction is $\mathrm{TiO} 2$. It has recently been reported that the $\mathrm{TiO} 2$ nanoparticles accelerated the rate of hydration and increased the degree of hydration [15]. Its photocatalytic characteristics have been mainly used to remove organic pollutants from surfaces directly exposed to ultraviolet radiations such as road pavements and cement-based façade finishing products [16]. Synthetic C-S-H has also been used as seeding agent during the hydration of cement phases [17]. The possibility of controlling the nature of hydration products through nucleation seeding of different types of pre-formed $\mathrm{C}-\mathrm{S}-\mathrm{H}$ was demonstrated.

Since the discovery of ferrites, about 80 years ago, much basic and applied research has been carried out to explore their potentials. During the 1940's and 1950 's, ferrites were systematized in the academic field, and today ferrite theory is well organized. From the 1950's, as radio and television sets spread, ferrites established a significant position in the industry, and now ferrites are one of the most essential materials in the electronics industry. One of these ferrites, $\mathrm{Cu}-\mathrm{Zn}$ ferrite was produced in 1936 as ferrite cores for antennas and intermediate frequency transformers in radios for the first time in Japan. Currently, this ferrite has many applications, including rotary transformers, noise filters, and multilayer ferrite chip components with regard to the magnetic semiconductor properties of ferrites [18].

\section{AIM OF THE RESEARCH}

The intention of this work is to examine the use of $\mathrm{Cu}-\mathrm{Zn}$ ferrites nanoparticles in the cement paste with respect to its compressive strength at age 7 and 28 days at normal and elevated temperatures up to 200 ${ }^{\circ} \mathrm{C}$ and $400{ }^{\circ} \mathrm{C}$ and Study Microstructure by SEM examinations.

\section{EXPERIMENTAL WORK}

\subsection{Materials}

\subsubsection{CuZn ferrite}

$\mathrm{Cu} 0.5 \mathrm{Zn} 0.5 \mathrm{Fe} 2 \mathrm{O} 4(\mathrm{Cu}-\mathrm{Zn}$ ferrite) nanoparticles were prepared using a common coprecipitation technique from $\mathrm{CuSO} 4, \mathrm{ZnSO} 4$, and $\mathrm{Fe} 2(\mathrm{SO} 4) 3$ chemicals according to the following equation:-

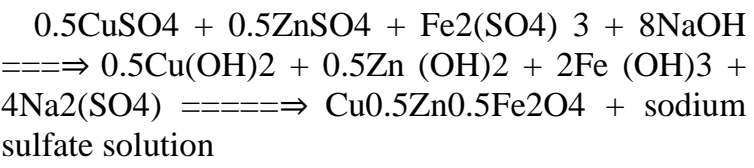

The sulfates were mixed in required stoichometric ratios in deionized (DI) water. $\mathrm{NaOH}$ solution was then added dropwise while stirring until the $\mathrm{pH}$ value becomes 12 . The mixture was continually stirred at $700 \mathrm{rpm}$ for $2 \mathrm{~h}$, while heated at $80^{\circ} \mathrm{C}$. A dark color was observed due to the formation of the ferrite particles. The mixture was allowed to settle the sediment. The mixture was washed ten times to remove the sodium sulfate solution. The powder sample was then dried at room temperature.

The x-ray powder diffraction (XRD) data was collected using $\mathrm{K} \alpha$ radiation. Approximately $200 \mathrm{mg}$ of powder was transferred to a glass XRD sample holder. This sample holder was then placed inside a X'Pert Graphics X-Ray Powder Diffractometer. Figure 1 shows the $\mathrm{X}$-ray diffraction pattern of $\mathrm{Cu} 0.5 \mathrm{Zn} 0.5 \mathrm{Fe} 2 \mathrm{O} 4$ nanoparticles, which clearly show the single phase of a spinel structure. Also, the mean particle size of around $12 \mathrm{~nm}$ was calculated from peak (311) of the X-ray diffractograms while employing Scherrer's formula. Transmission Electronic Microscopic (TEM) was carried out in National Research Center (NRC) at Physics Department using type JEOL - JEM - 1230 of magnification up to 60000 was employed to test the $\mathrm{Cu} 0.5 \mathrm{Zn} 0.5 \mathrm{Fe} 2 \mathrm{O} 4$ powders. Figure 2 shows the morphologies of the obtained $\mathrm{Cu}-\mathrm{Zn}$ ferrites nanoparticles. It can be observed that TEM micrographs reveal that the obtained ferrite participles are almost uniform with average size about $13 \mathrm{~nm}$. This value is very close to that being calculated using Scherrer's formula. 


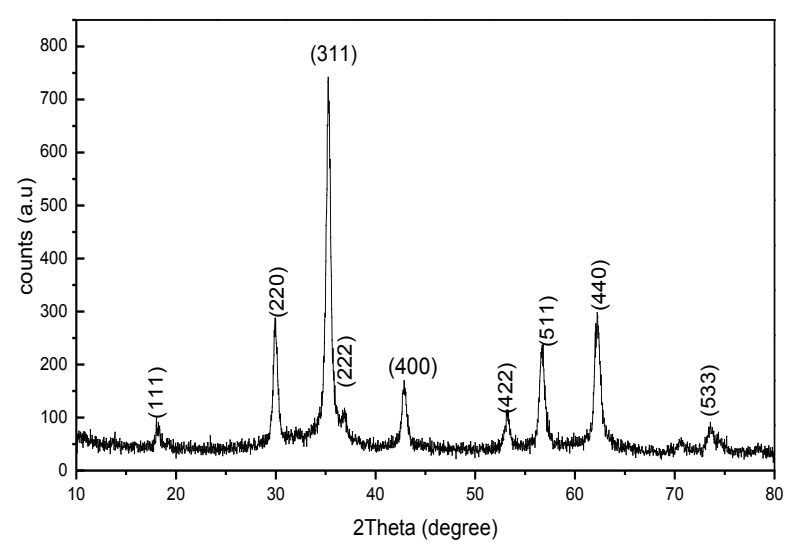

Fig. 1 XRD patterns of the $\mathrm{Cu}_{0.5} \mathrm{Zn}_{0.5} \mathrm{Fe}_{2} \mathrm{O}_{4}$
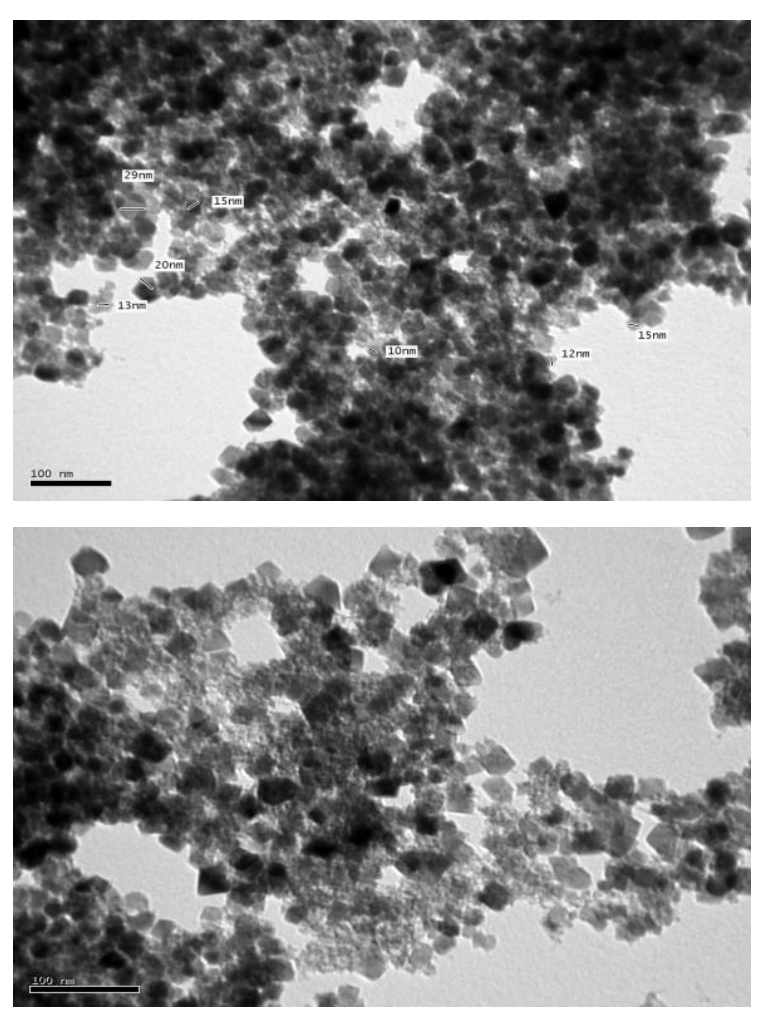

Fig. 2 TEM photographs of $\mathrm{Cu}_{0.5} \mathrm{Zn}_{0.5} \mathrm{Fe}_{2} \mathrm{O}_{4}$

\subsubsection{Cement}

Ordinary Portland cement (OPC) was used of type (CE M1 52.5N) according to E.S.S. (4756-1-2006) obtained from SINAI cement Factory in Egypt. The chemical composition of OPC is shown in Table 1.

\subsubsection{Sand}

Siliceons sand from El-Khatatba was used. The sand was clean, free from clay and other impurities. Specific gravity and volume weight of sand are shown in Table 2.
Table 1, Chemical properties of ordinary Portland (SINAI) Cement.

\begin{tabular}{|c|c|c|}
\hline Silicon Dioxide & $\mathrm{SiO}_{2}$ & $19.8 \%$ \\
\hline Aluminium Oxide & $\mathrm{Al}_{2} \mathrm{O}_{3}$ & $4.9 \%$ \\
\hline Ferric Oxide & $\mathrm{Fe}_{2} \mathrm{O}_{3}$ & $3.30 \%$ \\
\hline Calcium Oxide & $\mathrm{CaO}$ & $64.00 \%$ \\
\hline Magnesium Oxide & $\mathrm{Mgo}$ & $1.00 \%$ \\
\hline Sulphur Trioxide & $\mathrm{SO}_{3}$ & $3.30 \%$ \\
\hline Loss of Ignition & $\mathrm{LOI}$ & $2.00 \%$ \\
\hline Free CAO & $\mathrm{CaO}$ & $2.00 \%$ \\
\hline Alkalis as & $\mathrm{Na}_{2} \mathrm{O}$ & $0.68 \% \%$ \\
\hline Chloride as & $\mathrm{Cl}$ & $0.02 \%$ \\
\hline Tricalcium Silicate & $\mathrm{C}_{3} \mathrm{~S}$ & $54.00 \%$ \\
\hline Dicalcium Silicate & $\mathrm{C} 2 \mathrm{~S}$ & $14.00 \%$ \\
\hline Tricalcium Aluminate & $\mathrm{CsA}$ & $7.20 \%$ \\
\hline $\begin{array}{c}\text { Tricalcium Alumino } \\
\text { Ferrice }\end{array}$ & $\mathrm{CoAF}$ & $9.80 \%$ \\
\hline
\end{tabular}

Table 2, Specific Gravity and Volume Weight of Fine aggregates

\begin{tabular}{|c|c|c|}
\hline Aggregate & $\begin{array}{c}\text { Specific } \\
\text { gravity }\end{array}$ & $\begin{array}{c}\text { Volume } \\
\text { weight } \mathrm{t} / \mathrm{m}^{3}\end{array}$ \\
\hline Natural sand & 2.62 & 1.802 \\
\hline
\end{tabular}

\subsubsection{Superplasticizer}

One type of Superplasticizer was used in the experimental work of this study, with a trade name Glenium SKY 510. Glenium sky 510 is a superplasticiser based on polycarboxylic ether (PCE) polymers. It is derived directly from the total Performance Control concept. Glenium sky 510 is specially engineered for ready-mix concrete. Its particular configuration allows its delayed absorption onto the cement particles and disperses them efficiently. As compared with other PCE superplasticisers, it is possible to obtain a high quality concrete mix with accelerated strength development and extended workability without delayed setting characteristics. the Technical Data/Typical Properties of the Glenium sky 510 are shown in Table 3.

Table 3, Technical Data/Typical Properties of the GLENIUM SKY 510

\begin{tabular}{|l|l|}
\hline Appearance & Brown liquid \\
\hline Specific gravity at $20^{\circ} \mathrm{C}:$ & $1.06 \mathrm{~kg} / \mathrm{m}^{3}$ \\
\hline Viscosity at $20^{\circ} \mathrm{C}:$ & $30-200 \mathrm{mPa} \mathrm{s}$ \\
\hline Solid content: & $26 \%$ \\
\hline pH value: & $5-8$ \\
\hline Chloride ion content: & $0.01 \%$ \\
\hline
\end{tabular}




\subsection{Preparation and Mixing procedures of Nano Ferrite Cement Composites (NFCC)}

Nano ferrite (N.F) was firstly hand mixed with water for 5 minutes to make a uniformly dispersed suspension. Next, N.F -water solution and cement were mixed in the rotary mixer with a flat beater for 3 minutes. After pouring the mixes into moulds $(20 \times 20 \times 20 \mathrm{~mm})$ for cement paste (Fig. 3) and $(70 \times 70 \times 70 \mathrm{~mm})$ for cement mortar, an electric vibrator was used to ensure good compaction. The specimens were then surface smoothed and covered with wet hessian. All specimens were remolded 1 day after casting.

Thereafter, they were cured in standard water tank until testing at age 7 and 28 days. After 28 days of curing, half specimens were tested in compression without exposing to elevated temperatures, as control specimens, and the others were transferred to electrical oven for drying at temperature $105 \pm 2 \mathrm{oC}$ for a period of 24 hours. After drying, the specimens were translated to an electrical symmetrical furnace for heating at 200 and 400 at a rate of $10 \mathrm{oC} / \mathrm{min}$ for a constant period of exposure, two hours. The specimens were left to cool naturally to room temperature, then the compression test was performed until failure. Three specimens were tested for each temperature and average values are reported.

The experimental program described herein is divided into two parts aiming at investigating the effect N.F on properties of cement paste and cement mortar

\subsubsection{Effect Of Nanoferrites On Mechanical Properties Of Cement Paste}

First group of test samples of N.F.C composite was prepared following the percentage shown in (Table 4), this group was prepared for the compression test for cement paste sample with dimensions of $(2 \times 2 \times 2) \mathrm{cm}$.

\subsubsection{Effect Of Nanoferrites On Mechanical Properties Of Cement Mortar}

Second group of test samples of N.F.C composite was prepared following the percentage shown in (Table 5). This group was prepared for the compression test for cement mortar sample with dimensions of $(7 \times 7 \times 7) \mathrm{cm}$.

\section{ANALYSIS and DISCUSSION OF TEST RESULTS}

\subsection{Cement paste test results}

Figure 4-a shows the compressive strength of the hardened cement pastes at age 7,28 days with added nanoferrites ratios.
At 7- days the compressive strength of the NF composites increased with increasing amounts of the added NF up to nearly $2 \%$ wt. The improving percentage of compressive strength reaches to about $32 \%$ with respect to the control paste. Evidently, increasing amount of the added NF more than $2 \%$ by weight degrades the compressive strength of the hardened pastes.

At 28- days the compressive strength of the NF composites increased with increasing amounts of the added NF up to nearly $1 \%$ wt. The improving percentage of compressive strength reaches to about $31 \%$ with respect to the control paste. Evidently, increasing amount of the added NF more than $1 \%$ by weight degrades the compressive strength of the hardened pastes.

Figure 4-b shows the compressive strength of the hardened cement pastes at age 28 days with added nanoferrites ratios when exposed to elevated temperature $200{ }^{\circ} \mathrm{C}, 400{ }^{\circ} \mathrm{C}$.

At 28- days the compressive strength of the NF composites that exposed to elevated temperature 200 ${ }^{\circ} \mathrm{C}$ increased with increasing amounts of the added NF up to nearly $1 \%$ wt. The improving percentage of compressive strength reaches to about $51 \%$ with respect to the control paste. Evidently, increasing amount of the added NF more than $1 \%$ by weight degrades the compressive strength of the hardened pastes.

At 28- days the compressive strength of the NF composites that exposed to elevated temperature 400 $\mathrm{C} 0$ increased with increasing amounts of the added NF up to nearly $1 \%$ wt. The improving percentage of compressive strength reaches to about $52 \%$ with respect to the control paste. Evidently, increasing amount of the added NF more than $1 \%$ by weight degrades the compressive strength of the hardened pastes.

Figure 4-c, Figure 4-d and Figure 4-e compares the compressive strength of the hardened cement pastes that aged with 28 days and added nanoferrites with different ratios and exposed to normal and elevated temperature $200{ }^{\circ} \mathrm{C}, 400{ }^{\circ} \mathrm{C}$.

The present results showed that the addition of NF can improve the compressive strength of cement paste.

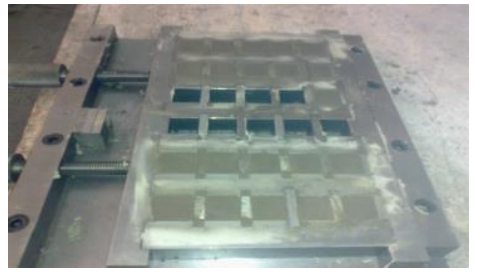

Fig. 3 mould for cement paste 
M. M. Kamal, M. Safan, S. I. Zaki, M. Eltabey, K.M. Abu El-hasan, " Development Of Compressive ..."

Table 4, Mix Compositions of Different NFCC Composites for cement paste

\begin{tabular}{|c|c|c|c|c|c|}
\hline Description & Control & $\begin{array}{c}\text { Nano Ferrite } \\
1 \%\end{array}$ & $\begin{array}{c}\text { Nano Ferrite } \\
2 \%\end{array}$ & $\begin{array}{c}\text { Nano Ferrite } \\
3 \%\end{array}$ & $\begin{array}{c}\text { Nano Ferrite } \\
4 \%\end{array}$ \\
\hline Mix. No & M0 & M1 & M2 & M3 & M4 \\
\hline OPC \% & 100 & 99 & 98 & 97 & 96 \\
\hline N.F \% & 0.0 & 1 & 2 & 3 & 4 \\
\hline W/C & 0.25 & 0.25 & 0.25 & 0.25 & 0.25 \\
\hline
\end{tabular}

Table 5, Mix Compositions of Different NFCC Composites for cement mortar

\begin{tabular}{|c|c|c|c|c|c|}
\hline Description & Control & Nano 1\% & Nano 2\% & Nano 3\% & Nano 4\% \\
\hline Mix. No & M0 & M1 & M2 & M3 & M4 \\
\hline OPC gm & 185 & 183.15 & 181.3 & 179.45 & 177.6 \\
\hline N.F gm & 0.0 & 1.85 & 3.7 & 5.55 & 7.4 \\
\hline $\mathrm{W} \mathrm{cm}^{3}$ & 74 & 74 & 74 & 74 & 74 \\
\hline Sand (gm) & 555 & 555 & 555 & 555 & 555 \\
\hline Glenium sky 510 $\left.\mathrm{cm}^{3}\right)$ & 5 & 7 & 9 & 11 & 13 \\
\hline
\end{tabular}

The behavior of the investigated paste mixtures incorporating different amounts of NF under different thermal loads is evaluated quantitively by measuring the retained (residual) strength after heat exposure. Two different temperatures were chosen for thermal loading, i.e. 200 and $400 \mathrm{oC}$. The results are shown in Figures 4-c, 4-d and 4.e. The test results indicated that each temperature range had a distinct pattern of strength loss or gain. It was generally noted that the compressive strength of all mixtures increase upon heating to $200 \mathrm{oC}$ with respect to the 28 day strengths of the corresponding mixtures. That is partly attributed to the evaporation of water which leads to friction increase between failure planes. This is believed to be further hydration processes. or possibly this level of heat catalyze hydration of the nonreacted cement products as a result of steam effect under the condition of the internal autoclaving formed in cement pastes. The increase of compressive strength can be partially due to the strengthened the hydrated cement past during the evaporation of free water, which leads to great Van der Wall's force as a result of cement gel layers moving closer to each other as shown in ref. [19-20], because transportation of moisture in paste is rather gradual, residual moisture in paste allowed accelerated hydration at the early stage of heating pastes to elevated temperatures.

At 28- days $1 \%$ NF the improving percentage of compressive strength of the NF composites and exposed to elevated temperature $200 \mathrm{oC}$ reaches to about $8 \%$ with respect to the same paste not exposed to elevated temperature and $16 \%$ with respect to the same paste exposed to elevated temperature $400 \mathrm{C} 0$, Table 6 shows the results clearly.

\subsection{Cement mortar test results}

Figure 5-a shows the compressive strength of the hardened cement mortar at age 7,28 days with added nanoferrites ratios.

At 7- days the compressive strength of the NF composites increased with increasing amounts of the added NF up to nearly $1 \%$ wt. The improving percentage of compressive strength reaches to about $11 \%$ with respect to the control mortar. Evidently, increasing amount of the added NF more than $1 \%$ by weight degrades the compressive strength of the hardened mortar.

Table 6, Compressive strength of hardened cement paste with and without nano ferrites

\begin{tabular}{|c|c|c|c|c|c|}
\hline \multirow{2}{*}{ Mix No. } & \multirow{2}{*}{ Mix description } & \multicolumn{4}{|c|}{ Compressive strength $\mathrm{kg} / \mathrm{cm}^{2}$} \\
\cline { 3 - 6 } & & 7-day & 28-day & T200 & T400 \\
\hline M0 & Control & 673.82 & 883.81 & 677.90 & 568.82 \\
\hline M1 & nanoferrite 1\% & 891.97 & 1263.04 & 1365.99 & 1162.11 \\
\hline M2 & nanoferrite 2\% & 980.66 & 1100.95 & 960.10 & 705.014 \\
\hline M3 & nanoferrite 3\% & 592.27 & 1103.17 & 787.84 & 635.78 \\
\hline M4 & nanoferrite 4\% & 550.47 & 970.69 & 797.25 & 904.89 \\
\hline
\end{tabular}



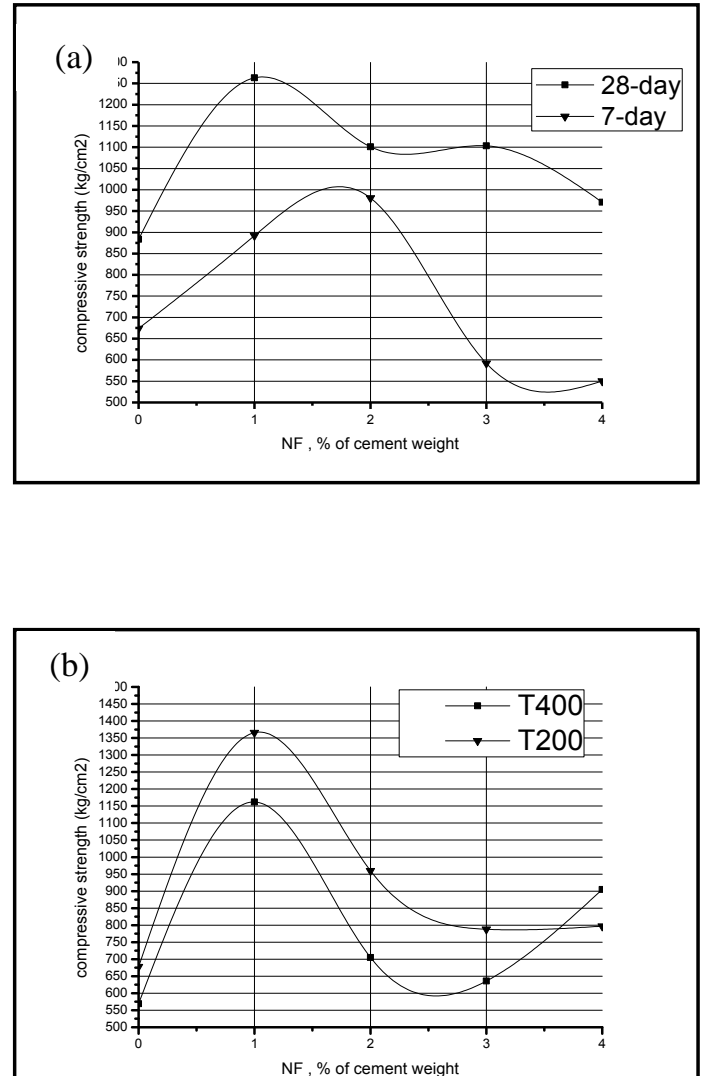

(c)

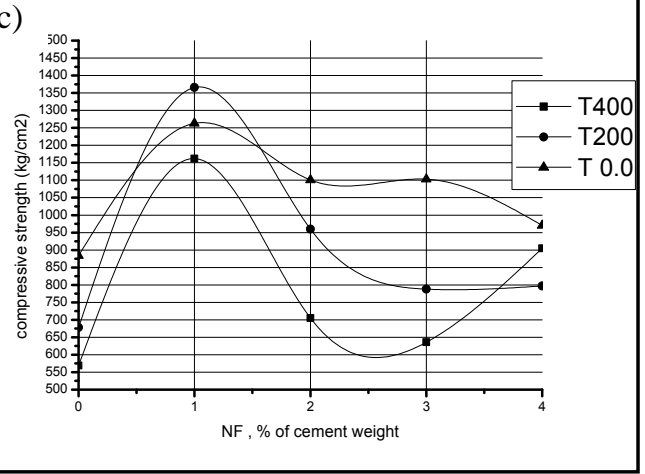

(d)

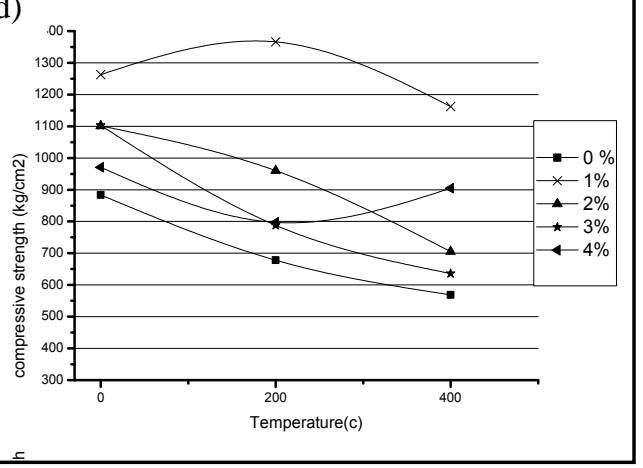

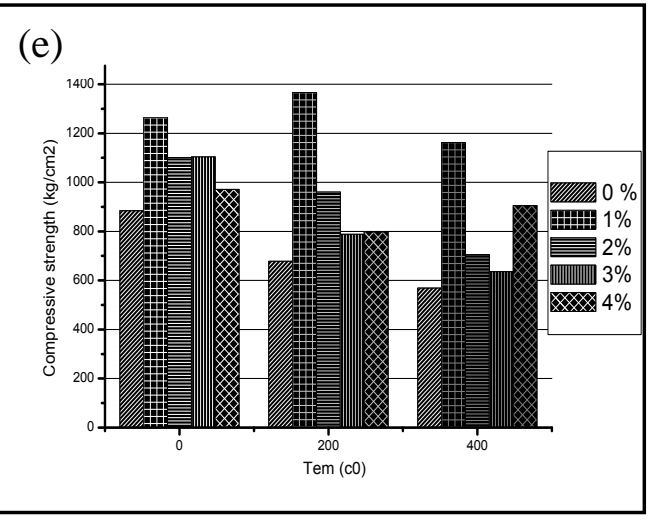

Fig. 4 Compressive Strength of NFCC with different Ratios of NF(for cement paste)

At 28- days the compressive strength of the NF composites increased with increasing amounts of the added NF up to nearly $1 \%$ wt. The improving percentage of compressive strength reaches to about $33 \%$ with respect to the control mortar. Evidently, increasing amount of the added NF more than $1 \%$ by weight degrades the compressive strength of the hardened mortar.

Figure 5-b shows the compressive strength of the hardened cement motrar at age 28 days with added nanoferrites ratios when exposed to elevated temperature $200 \mathrm{oC}, 400 \mathrm{oC}$.

At 28- days the compressive strength of the NF composites that exposed to elevated temperature 200 $\mathrm{C} 0$ increased with increasing amounts of the added NF up to nearly $3 \%$ wt. The improving percentage of compressive strength reaches to about $22 \%$ with respect to the control mortar.

At 28- days the compressive strength of the NF composites that exposed to elevated temperature 400 $\mathrm{C} 0$ increased with increasing amounts of the added NF up to nearly $1 \%$ wt. The improving percentage of compressive strength reaches to about $35 \%$ with respect to the control mortar. Evidently, increasing amount of the added NF more than $1 \%$ by weight degrades the compressive strength of the hardened mortar.

Figure 5-c, Figure 5-d and Figure 5-e compares the compressive strength of the hardened cement mortar that aged with 28 days and added nanoferrites with different ratios and exposed to normal and elevated temperature $200 \mathrm{oC}, 400 \mathrm{oC}$.

The present results showed that the addition of NF can improve the compressive strength of cement mortar.

At 28- days $1 \% \mathrm{NF}$ the improving percentage of compressive strength of the NF composites that exposed to elevated temperature $400 \mathrm{oC}$ reaches to about $5 \%$ with respect to the same mortar not exposed to elevated temperature and $25 \%$ with respect to the same mortar exposed to elevated temperature $400 \circ \mathrm{C}$, Table 7 shows the results clearly. 
M. M. Kamal, M. Safan, S. I. Zaki, M. Eltabey, K.M. Abu El-hasan, " Development Of Compressive ..."

At 28- days and add 3\% NF the improving percentage of compressive strength of the NF composites that exposed to elevated temperature $400 \mathrm{oC}$ reaches to about $1 \%$ with respect to the same mortar not exposed to elevated temperature and $0.8 \%$ with respect to the same mortar exposed to elevated temperature $200 \mathrm{oC}$.

\subsection{Microstructure Study}

To verify the mechanism predicted by compressive strength test, SEM examinations were performed. Additions of nanoferrite particles were found to influence hydration behavior and lead to differences in microstructure of cement paste. SEM tests were carried out for control cement paste (without nanoferrite) and for cement pastes containing nanoferrites of amounts 1 and $2 \%$ by weight of cementitious materials after 28-days. Fig.6 shows SEM micrograph of control sample after 28-days, it can be seen that calcium silicate hydrate is exisisted in isolated points surrounded by many needle hydrates and some cracks. On the other hand the microstructure of the mixture containing nanoferrites with ratios 1 and $2 \%$ revealed a very densw,compact formation of hydration ptroduct with big crystals as shown in Fig.7 and Fig. 8.

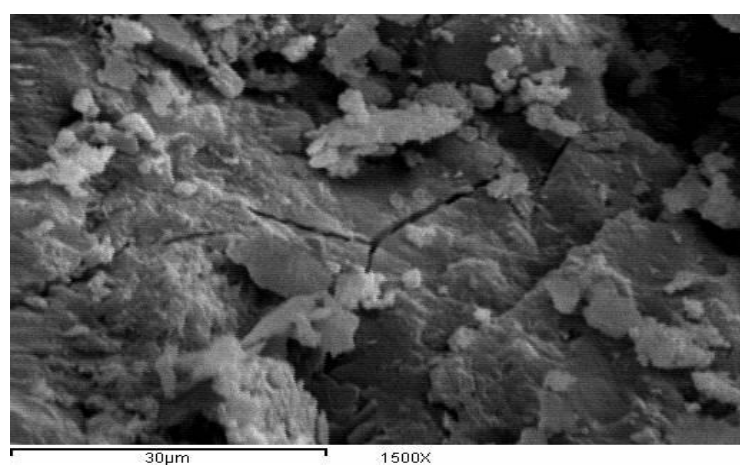

Fig. 6 SEM micrograph of control sample after 28- days

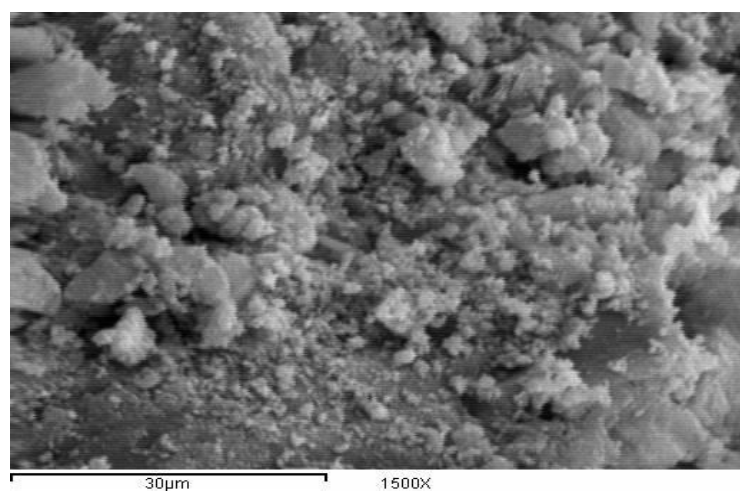

Fig. 7 SEM micrograph of nanoferrites $(1 \%)$ cement paste sample after 28-days

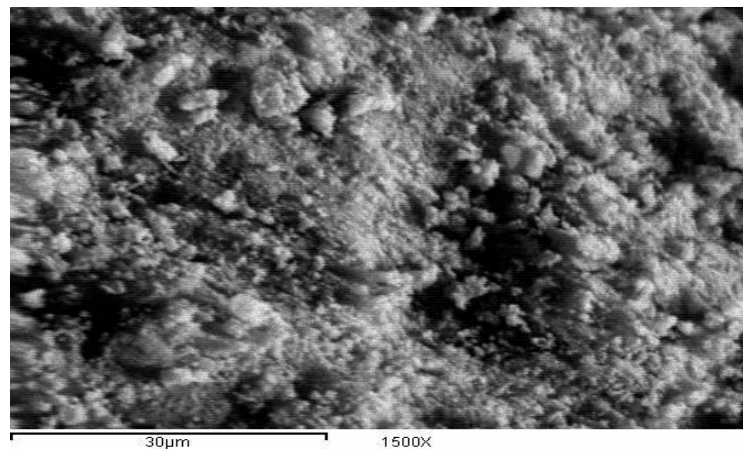

Fig. 8 SEM micrograph of nanoferrites $(2 \%)$ cement paste sample after 28-days

(a)

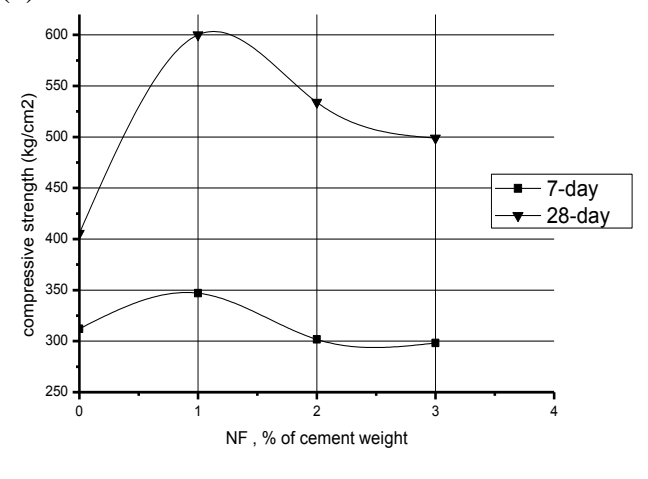

(b)

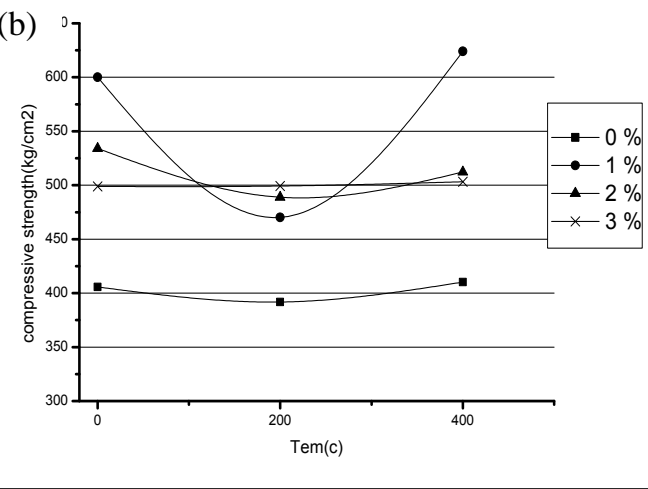

(c)

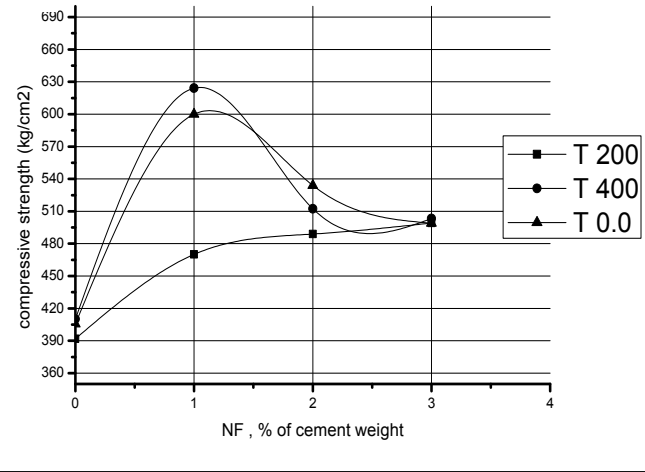



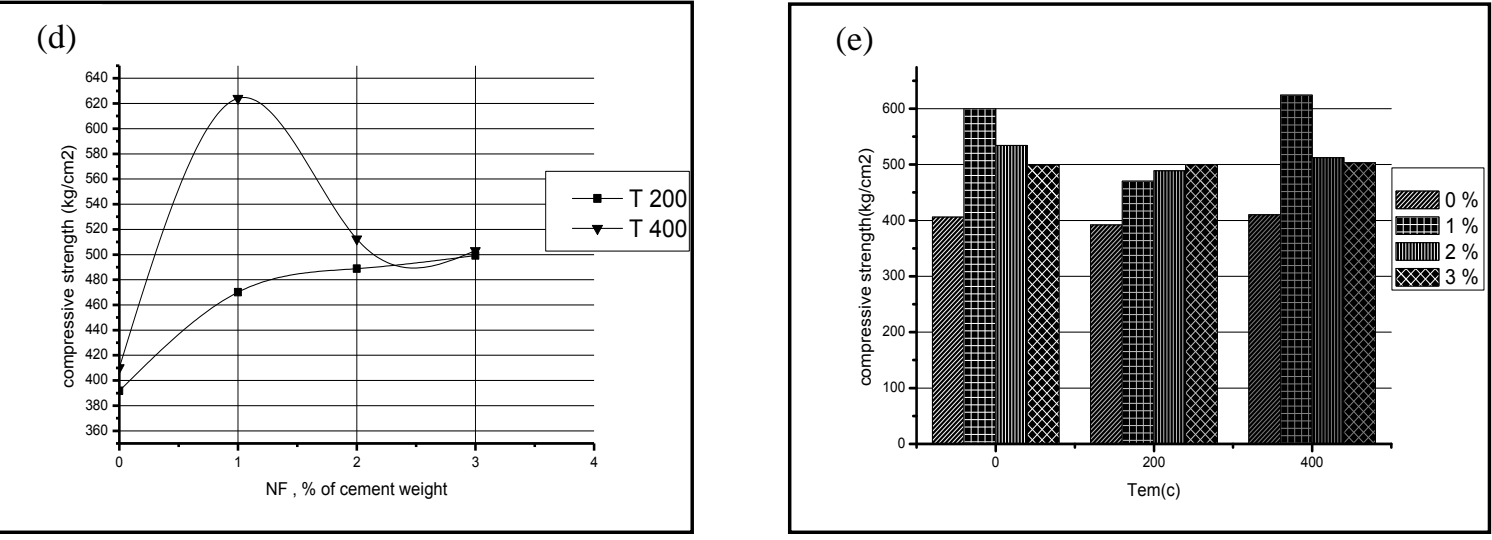

Fig. 5 Compressive Strength of NFCC with different Ratios of NF(for cement mortar

Table 7, Properties of hardened cement mortar with and without nano particles

\begin{tabular}{|c|c|c|c|c|c|}
\hline \multirow{2}{*}{ Mix No. } & \multirow{3}{*}{ Mix description } & \multicolumn{4}{|c|}{ Compressive strength kg/cm ${ }^{2}$} \\
\cline { 3 - 6 } & & 7-day & 28-day & T200 & \multirow{2}{*}{ T400 } \\
\hline M0 & Control & 312.06 & 405.68 & 391.81 & 410.20 \\
\hline M1 & nanoferrite 1\% & 347 & 600 & 470.1 & 624.12 \\
\hline M2 & nanoferrite 2\% & 301.65 & 533.97 & 488.86 & 512.3 \\
\hline M3 & nanoferrite 3\% & 298.2 & 498.92 & 499.2 & 503.2 \\
\hline
\end{tabular}

\section{CONCLUSIONS}

Based on the results of the experimental work described in this research, the following main conclusions can be drawn. The results reported in this study provide new data on the fire performance of cement-NF composites, when exposed to temperatures up to $400 \mathrm{oC}$. These results can be considered as a preliminary stage of research and the ultimate performance of the cement-NF composites under development remain unknown when exposed to elevated temperatures, the experimental results have led to the following conclusions:

1- The properties of cement paste and cement mortar are improved by adding of nano powders, since nano ferrite particles fill the voids between cement grains and improve the mix.

2- The incorporating OPC by NF was found to influence hydration behavior and led to differences in the microstructure of the hardened pastes.

3- The improving percentage of compressive strength when nano ferrite was added reache to about $52 \%$ with respect to the control paste and about $35 \%$ with respect to the control mortar.

4- Nanoferrites addition results in significant increase in cement paste compressive strength after 28-days and the optimum amount of Nano ferrites is $1 \%$ by weight of cementitious material.

5- Nanoferrites addition results in significant increase in cement mortar compressive strength after 28-days and the optimum amount of Nano ferrites is $1 \%$ by weight of cementitious material.

6- Increasing amount of the added NF more than 1 $\%$ by weight degrades the compressive strength of the hardened pastes and mortars.

7- The microstructure of the hardened cement pastes containing NF revealed a dense, compact formation of hydration products.

8- Nano ferrites cement mortar requires additional amount of water or super plasticizer to maintain the same workability level.

9- Nano ferrites in cement matrix not only modified the compressive strength at room temperature, but also modified the compressive strength after exposure to elevated temperatures up to $400 \mathrm{oC}$.

\section{REFERENCES}

[1] Balaguru, P. N. (2005), "Nanotechnology and Concrete: Background, Opportunities and Challenges." Proceedings of the International Conference - Application of Technology in Concrete Design, Scotland, UK, p.113-122.

[2] Li, G. (2004), "Properties of High-Volume Fly Ash Concrete Incorporating Nano-SiO2." Cement and Concrete Research, vol.34, p.10431049.

[3] Bigley C. and Greenwood P. (2003), "Using Silica to Control Bleed and Segregation in Self Compacting Concrete." Concrete, vol. 37, no. 2, p. $43-45$ 
M. M. Kamal, M. Safan, S. I. Zaki, M. Eltabey, K.M. Abu El-hasan, " Development Of Compressive ..."

[4] Zaki S. I. and Ragab Khaled S. (2009), "How nanotechnology can change concrete industry", 1st International Conference on Sustainable Built Environment Infrastructures in Developing Countries, ISSN 2170-0095, Oran, Algeria, Vol. 1, 407-414.

[5] Qing, Y.; Zenan, Z.; Deyu, K.; Rongshen (2009), "Influence of nano-SiO2 addition on properties of hardened cement paste as compared with silica fume". Constr. Build. Mater. 2005, 21, 539-545.

[6] Korpa, A.; Trettin, R. Pyrogene (2005) “ nanooxides in modern cement-based composites". In Proceedings of 2nd International Symposium on Nanotechnology in Construction, Bilbao, Spain, pp. 313-320.

[7] Lin, K.L.; Chang, W.C.; Lin, D.F.; Luo, H.L; Tsai, M.C(2008), "Effects of nano-SiO2 and different ash particle sizes on sludge ashcement mortar". J. Environ. Manag. 88, 708714.

[8] Li, H.; Xiao, H.; Yuan, J.; Ou, J. (2004)" Microstructure of cement mortar with nanoparticles". Compos. B: Eng. 35, 185-159.

[9] [9] Li, H.; Zhang, M.; Ou, J. (2006). "Abrasion resistance of concrete containing nano-particles for pavement".Wear 260, 1262-1266.

[10] Han, B.; Guan, X.; Ou, J. (2004). "Specific resistance and pressure-sensitivity of cement paste admixing with nano-TiO2 and carbon fiber”. J. Chin. Ceram. Soc. 32, 884-887.

[11] Abbs R., (2009), "Influence of nano-silica addition on properties of conventional and ultra-high performance concretes", HBRC Journal, Vol. 20, No. 20, 1-13.

[12] Xiong, G.; Deng, M.; Xu, L.; Tang, M. (2006), "Properties of cement-based composites by doping nano- TiO2". J. Chin. Ceram. Soc. 34, 1158-1161.
[13] Sato, T.; Beaudoin, J.J.; Ramachandran, V.S.; Mitchell, L.D.; Tumidajski, P.J. (2007), "Thermal decomposition of nanoparticulate $\mathrm{Ca}(\mathrm{OH}) 2-$ anomalous effects". Adv. Cem. Res. 19, 1-7.

[14] [14] Colston, S.L.; O'Connor, D.; Barnes, P.; Mayes, E.L.; Mann, S.; Freimuth, H.; Ehrfeld, W. (2000), "Functional micro-concrete: The incorporation of zeolites and inorganic nanoparticles into cement micro-structures". J. Mater. Sci. Lett. 19, 1085-1088.

[15] Lee, B.Y.; Thomas, J.J.; Treager, M.; Kurtis, K.E. (2009), "Influence of $\mathrm{TiO} 2$ Nanoparticles on Early C3S Hydration. Nanotechnology of Concrete": The Next Big Thing is Small. In ACI Convention, New Orleans, LA, USA, 812; CD-ROM (SP-267), pp. 35-44.

[16] Cassar, L. (2007) "Nanotechnology and photocalatalysis in cementitious materials". In Proceedings of 2nd International Symposium on Nanotechnology in Construction, NICOM2, Bilbao, Spain, 13- pp. 277-283.

[17] Alizadeh, R.; Raki, L.; Makar, J.M.; Beaudoin, J.J.; Mou drakovski, I. (2009), "Hydration of tricalcium silicate in the presence of synthetic calcium silicate hydrate". J. Mater. Chem. 19,7937-7946.

[18] Sugimoto, M. (1999), "The Past, Present, and Future of Ferrites", Journal of the American Ceramic Society, Volume 82, No. (2), pp. 269-280

[19] Dias D. P. S., Khoury G. A. and Sullivan P. J. E.( 1990), "Mechanical properties of hardened cement paste exposed to temperature up to 700 oC", 1292F, ACI Materials Journal, 87(2), 1605.

[20] Khoury G. A. (1992), "Compressive strength of concrete at high temperatures", Mag. Concr. Res., 44(161), 291-309. 